\title{
Case Study of Obsessive-Compulsive Disorder (OCD)
}

\author{
Muhammad Zafar Iqbal* \\ Department of Hypnotherapist and Psychotherapist, Islamabad, Pakistan
}

*Corresponding author: Muhammad Zafar Iqbal, Department of Hypnotherapist and

Psychotherapist, Islamabad, Pakistan.

Received Date: April 05, 2019

Published Date: May 08, 2019

\section{Abstract}

Background: This document pertains of idiographic research; the case study of Obsessive-compulsive disorder (OCD). The objective of this case study was to reaffirm the efficacy of Fear-Stimuli Identification Therapy (FSIT). FSIT was used to eliminate the symptoms of OCD in a client, a successful treatment for disorders in different cases [1-8].

Method: Initially seven sessions of semi-structured interviews were conducted with client to dig out the reasons/causes of the disorder. Diagnostic and Statistical Manual of Mental Disorders, Fifth Edition (DSM-V) was consulted for diagnosis [9]. Fear Stimuli Identification Therapy (FSIT) was used as therapeutic tool.

Results: After diagnosis, five sessions per week, a total of eighty-three sessions were conducted of FSIT. Positive behavioral change observed in client which proved the efficacy of FSIT.

Conclusion: Clinical observations during treatment indicated a gradual positive change in client's personality. The client and her husband reported positive behavioral changes in different domains of life. The difference between pre-assessment and post- assessment confirmed precision of hypotheses and efficacy of FSIT.

Keywords: Obsessive compulsive disorder; Symptoms; Assessment; Case study; Idiographic

\section{Introduction}

The subject of the disorder was Mrs. S.H. (Initials of real name), age 38 years, a Housewife. The client was referred to therapist clinic by a fellow psychologist from a metropolitan southern city. She had been under treatment of various psychiatrists and psychologists in her city, but the client did not improve. She contacted therapist online. Client reported about her compulsively repeating some acts in her daily life as obsession. She supposed that her mind was persistently occupied by some specific thoughts and her act of repeating some actions is a result of these thoughts. Therapist contacted her husband for more details about the behavior of client. Aggressive behavior, Sleeplessness, weeping without any apparent reason, Breath shortness, Uncontrollable thoughts, Repetition of some of her daily life acts Symptoms are reported by Client and her husband.

\section{Method}

- Participants

Mrs. S.H, Client, Client's Husband and Therapist.

- Instrument

No instrument/ Material used in this case study.

\section{Procedure}

As already mentioned, in the first seven sessions, semistructured interviews were conducted with Mrs. S.H. and her husband. In the subsequent eighty-three sessions Mrs. S.H. was asked to write about specific topics suggested by therapist. Crossquestioning was carried out over the ideas mentioned in the writings by client. After diagnosis of OCD, treatment was started in the light of FSIT method. Five sessions per week were conducted and total of eighty-three sessions were conducted. It may be noted that all these sessions were carried out online [4].

\section{Assessment}

Following facts were explored through initial interviews which were 'Semi-structured'. These interviews revealed that at the age of 11 years, one day she (client) returned back from school in the company of her close friend N.S. After reaching home she and her parents received the shocking news of death of N.S. They were told that N.S. had eaten something poisonous and had died instantly. S.H., the client was shocked deeply. The incident of her friend's death became a stimulant for fear instinct. 
At the day of her funeral, she feared to see the face of her deceased friend and couldn't enter the room where the dead body was laid. After the death of her friend another death happened that provoke more fear about the death. Her grandmother died six months later after her friend's death. She, for the first time watched her grandmother's dead body wrapped in white clothes which leaves bad marks on her memory that she stopped wearing white cloth especially white scarf or shawl for rest of her life.

Another incident happened after one year of marriage. Her father-in-law died in ambulance due to sudden attack. The ambulance became a stimulus for her fear. After developing death phobia, each death intensified the sense of fear in her unconscious mind. In the course of time she became a religious orator orator of a specific type as she used to narrate rhetorically upon the miseries and sorrows which had emerged from the unfortunate events of wars of Islamic history. By performing so, she felt some sort of relief as this became a source of catharsis for her. She was strongly obsessed by the idea of death that her mind often used to get stuck at the thought of her friend's death. While doing random stuff she often found herself motionless due to the flashback of her friend's death and to get rid from this obsession she used to force her mind to think of other things. Similarly, she taps her mobile phone with her fingers frequently while obsessing about her brother's death. During one of Skype sessions she informed the therapist that after marriage she finds it more difficult to cope with the obsessive ideas.

\section{Therapist and treatment}

It is single case experimental study which is handled by only one therapist and after taking history, it was diagnosed that client was suffering from OCD and the treatment was carried out accordingly: As per procedure of SFW (specific free writing; one of procedures of FSIT), in very first session of treatment, client was asked to pen down her ideas freely on the topic "death". She was asked to put a cross mark for each time whenever she feels stuck or blank-minded during writing process. The piece of writing was received by E-mail. She told that during the process of writing she felt burden at the occipital region of head and pain and burden on her shoulders. In the view of writing, client was cross-questioned over the ideas mentioned in the writing. After fifteen minutes, client went through a deep spell of drowsiness. The session was ended at this point. This drowsiness continued in the next five sessions during questioning over her writing. The extreme hate for and fear of her own death which had previously gripped her unconscious level of mind was identified and brought out clearly as it had been suppressed by patient's unconscious for a very long time in past. Next topics given to write about were: "White shawl" (considered as coffin), "Bathing place" for a dead person at holy shrine, the "couch" upon which dead body is laid down after bath, "Ambulance", "Funeral Bus" and "Thoughts about dead persons". During writing practice, same mental and physical response was reported each time as it was observed first time that was a result of unconscious resistance to express fears. The thoughts of "white shawl", "coffin" and ambulance etc caused the fear of her own death and ultimately became reason for OCD. In last sessions of treatment, the mentioned above things were rooted out and recovered from OCD.

\section{Result}

The symptoms of disorder gradually removed during therapy. Feedback obtained from husband \& client was obtained regularly which indicated the positive changes in client behavior of. Result also proved the efficacy of FSIT method empirically.

\section{Discussion}

Brief description of a client's social and family environment was obtained in order to comprehend the main causes of Mrs. S.H.'s disorder and this procedure is adopted in most of the cases treated by therapist. In this particular case following information came into knowledge of therapist. Mrs. S.H. was 38 years old, housewife and a lecturer in college. However, due to lack of concentration, disturbed sleep and unreasonable repetition of different acts of routine, her daily routine was badly affected, and it made her much depressed and disappointed. Mrs. S.H. was not much social person since her childhood. She had always tried to avoid social gatherings and people. After starting the problem of OCD, her social life became more difficult. It made her more depressed, but interestingly and contrarily, she had managed to carry out routine life activities as above the level of an ordinary social individual. She had been performing as an orator at religious gatherings. But she always avoided elaborating over the topics of death and afterlife in her speeches. No family history of OCD or any other psychiatric disorder was found and she. had no special medical/psychiatric problems in her childhood [10].

Fear Stimuli Identification Therapy (FSIT): Fear-Stimuli Identification Therapy (FSIT) is based upon the perception that some of the incidents (mostly the sudden incidents) in the early age of a child become stimuli for fear instinct which cast negative effects over the personality of a child and become reason for one or the other type of disorder. FSIT investigates and digs out such events from a person's unconscious, which play as stimuli for fear instinct. In a later stage of life, if a person happens to face a situation or pass through an event having resemblance to that which he/ she had already faced in her/his childhood or early age of life, the present event becomes a strong stimulant for fear instinct as the previous incident is recalled.

\section{Conclusion}

Feedback \& Clinical observations during treatment also indicated a gradual positive change in her personality. The difference between pre-assessment and post- assessment confirmed precision of hypotheses and efficacy of FSIT. Feedback was obtained on weekly basis for a period of three was confirmed that there was no reoccurrence of the disorder's symptoms anymore.

\section{Acknowledgement}

None.

\section{Conflict of Interest}

This research did not receive any specific grant from funding agencies in the public, commercial, or not-for-profit sectors.

\section{References}

1. Ejaz M, Iqbal MZ (2016) Case Study of Major Depressive Disorder. J Clin Case Rep 6: 698. 
2. Iqbal MZ, Awan SN (2016) Case Study of Genophobia and Anxiety. J Depress Anxiety S2: 013.

3. Iqbal MZ, Bibi S (2017) Case Study of Panic Attacks. J Psychol Psychother $7: 306$.

4. Iqbal MZ, Bibi S (2016) Treatment of Psychosis through Fear-Stimuli Identification Therapy (FSIT): A Case Report. Brain Disorders \& Therapy 5(3): 221-224.

5. Iqbal MZ, Ejaz M (2016) Case Study of Schizophrenia (Paranoid). J Clin Case Rep 6: 779.
6. Iqbal MZ, Ejaz M (2016) Case Study of Functional Neurological Disorder (Aphonic). J Psychol Psychother 6(1): 243.

7. Iqbal MZ, un Awan SN (2016) Case Study of Major Depression. J Med Diagn Meth 5: 214.

8. Iqbal Z (2015) Case of Anxiety. J Psychol Clin Psychiatry 2(4): 79.

9. American Psychiatric Association (2000) Diagnostic and statistical manual of mental disorders (DSM-IV-TR). Washington DC, USA.

10. Muhammad Zafar Iqbal (2017) Case study of Obsessive-Compulsive Disorder (OCD). Journal of Behavioral Health 6(2): 99-102. 